\title{
A Model for Probabilistic Assessment of Phytosanitary Risk Reduction Measures
}

\author{
Mark R. Powell, United States Department of Agriculture Office of Risk Assessment and Cost Benefit Analysis, \\ Washington, DC 20250
}

\begin{abstract}
Powell, M. R. 2002. A model for probabilistic assessment of phytosanitary risk reduction measures. Plant Dis. 86:552-557.

Ideally, a phytosanitary performance standard would be defined as a probabilistic tolerance. For treatments such as solid wood pasteurization, this could be operationalized by stating with a specific degree of confidence that the treatment failure rate for a sentinel pest should be less than a defined level (e.g., $X \%$ confidence that the wood heat treatment failure rate for pest $Y$ does not exceed $Z \%$ ). This article illustrates a probabilistic approach to developing a phytosanitary performance standard, using heat treatment of the wood-inhabiting fungus Postia placenta as an example. The uncertainty about the proportion of wood blocks in which $P$. placenta survives after treatment is characterized by the Beta distribution, subject to the biological constraint that survival should decrease monotonically with increased time and temperature. Monte Carlo simulation techniques are then used to generate a probabilistic response surface relating proportion survival to treatment time and temperature. This modeling approach relaxes the parametric assumptions associated with traditional statistical methods for fitting response surfaces and is more flexible than conventional methods, resulting in a better fit to the observed data.
\end{abstract}

The World Trade Organization (WTO) Agreement on Sanitary and Phytosanitary Measures (the "SPS Agreement") seeks to ensure that SPS measures do not result in unnecessary barriers to international trade by requiring that countries establish or maintain SPS measures on the basis of scientific risk assessment (11). Given the downward pressure on international trade tariffs and agricultural subsidies resulting from the 1994 conclusion of the Uruguay Round of the General Agreement on Tariffs and Trade (GATT), many observers expect SPS measures to be a growing area of trade disputes as countries seek to protect their producers from international competition. An SPS restriction can be a very effective

Corresponding author: M. R. Powell

E-mail: mpowell@oce.usda.gov

The opinions expressed herein are the views of the author and do not necessarily reflect the official policy or position of the United States Department of Agriculture. Reference herein to any specific commercial products, process, or service by trade name, trademark, manufacturer, or otherwise, does not necessarily constitute or imply its endorsement, recommendation, or favoring by the United States Government.

Accepted for publication 13 January 2002.

Publication no. D-2002-0311-01S

This article is in the public domain and not copyrightable. It may be freely reprinted with customary crediting of the source. The American Phytopathological Society, 2002. protectionist device and, because of its technical complexity, a particularly deceptive and difficult barrier to challenge. At the same time, however, the SPS Agreement acknowledges the legitimate use of SPS measures (which include laws, regulations, and procedures such as inspection and treatment) to restrict trade to protect against bona fide risks to human, animal, and plant health.

The SPS Agreement calls for the widest possible international harmonization of SPS measures. With respect to phytosanitary measures, the SPS Agreement identifies the international and regional organizations operating within the International Plant Protection Convention (IPPC) framework to promote the harmonization objective. The SPS Agreement permits a member to introduce or maintain SPS measures that result in a higher level of protection than would be achieved by relevant international standards if the member determines, on the basis of a risk assessment, that the international standards are insufficient to achieve the level of protection the member determines to be appropriate. Nevertheless, the SPS Agreement obliges members to ensure that such measures are not more trade restrictive than required to achieve their appropriate level of phytosanitary protection, to avoid arbitrary or unjustifiable distinctions in the levels of protection deemed appropriate, to accept as equivalent alternative SPS measures demonstrated to achieve the appropri- ate level of protection, and to make transparent the determination of the appropriate level of sanitary or phytosanitary protection.

Wood-inhabiting pests of quarantine importance include the Asian longhorned beetle (Anoplophora glabripennis) and pinewood nematode (Bursaphelenchus xylophilus). A woodboring insect native to China and Korea, the Asian longhorned beetle commonly infests living, healthy trees. In 1998, after detection of Asian longhorned beetle infestations in urban hardwood populations in New York and Illinois, the United States Department of Agriculture (USDA) promulgated an interim rule adding treatment and documentation requirements for solid wood packing material (SWPM; e.g., pallets and crates) from China. It is estimated that between one-quarter and one-half of China's exports to the United States (valued at $\$ 42$ billion in 1999) were affected by the change (3).

The pinewood nematode infects conifers, especially pines, and is vectored by pine sawyer beetles of the genus Monochamus. The pinewood nematode is indigenous to North America, where it is rarely a primary pathogen, but it has caused extensive mortality in pines in Japan. The European Union (EU) began regulating U.S. and Canadian shipments of unprocessed coniferous wood products in the early 1990 s, following interceptions of the pinewood nematode in shipments of wood chips to Finland and Sweden. European concern over the pinewood nematode subsequently heightened after an outbreak in Portugal and interceptions of the nematode in SWPM from the United States, Canada, China, and Japan. In 2001, the EU adopted emergency measures requiring the treatment and marking of all coniferous nonmanufactured wood packing material originating in the United States, Canada, China, or Japan. EU imports from the United States were valued at approximately $\$ 150$ billion in 1999 , and the USDA expects that a significant portion of U.S. exports will be affected by the measures, because most goods are transported using SWPM and a substantial portion of pallets and containers are made entirely of or partially of coniferous lumber. It is estimated that well over one-half of the $\$ 1.7$ trillion worth of goods that entered or left 
the United States in 1999 used some form of SWPM. In 2000, the IPPC Interim Commission on Phytosanitary Measures initiated development of international guidelines for regulating SWPM (3).

Current IPPC guidelines for pest risk analysis provide some direction for assessing the efficacy and impact of various options in reducing phytosanitary risk to an acceptable level. The guidelines state that the risk reduction options should be evaluated in terms of several criteria: biological effectiveness, cost/benefit of implementation, impact on existing regulations, commercial impact, social impact, phytosanitary policy considerations, time to implement a new regulation, efficacy against other quarantine pests, and environmental impact (5). The recently adopted IPPC standard for quarantine pest risk analysis elaborates on the evaluation of risk reduction procedures, indicating that the probability that the pest will go undetected during inspection or survive other existing phytosanitary procedures should be estimated (6). This provision is noteworthy in that it introduces the key concept that the efficacy of risk reduction procedures is probabilistic-not deterministic. Analysis of the performance of risk reduction measures is subject to both variability (arising from random stochasticity) and uncertainty (due to the limits of the current state of knowledge).

Historically, evaluations of the efficacy of phytosanitary measures have tended toward either simple binary determinations (effective or ineffective) that fail to explicitly account for the probabilistic nature of such measures, or toward subjective ordinal ranking statements (high, medium, low) based on professional judgment informed by available scientific information. Faced with the new challenge of developing commodity- and pest-specific international phytosanitary standards (e.g., for SWPM and citrus canker), and recognizing the lack of attention that has been paid to analyzing the efficacy of risk reduction measures, the ICPM recently recommended the development of a new international standard for assessing the efficacy of phytosanitary measures (4).

There is broad consensus within the risk analysis field-a discipline of decision sciences-that the level of regulatory analysis should be commensurate with the importance of the problem and the consequences of additional detail to the regulatory decision (1). Furthermore, the economic and political stakes largely determine the extent to which a regulatory agency's use of science is controversial (9). It seems plausible, however, that an international trade dispute may arise in which a rudimentary analysis of phytosanitary measure efficacy is deemed by stakeholders or reviewers (e.g., courts or dispute resolution panels) to be insufficient to support a controversial standard. The measure conceivably could be challenged as being unnecessarily trade restrictive, insufficiently protective, or, perhaps most likely, both. This, and the increased economic stakes of multilateral phytosanitary measures affecting large volumes of trade, are prompting a more rigorous and more quantitative approach to phytosanitary risk assessment than heretofore.

Through its equivalence, transparency, and related provisions, the SPS Agreement encourages the development of risk-based standards. Ideally, a phytosanitary performance standard would be defined as a probabilistic tolerance. For treatments such as solid wood pasteurization, this could be operationalized by stating that the heat treatment failure rate for a sentinel pest should be less than a defined level with a specific degree of confidence (e.g., $X \%$ confidence that the wood heat treatment failure rate for pest $Y$ does not exceed $Z \%$ ). This article illustrates one approach to developing such a standard based on available data. The example presented is the effect of heat treatment on the survival of deep wood-inhabiting pests. Deep-wood pests, such as wood borers and deep-wood pathogens, are of particular concern because they are not susceptible to bark removal or surface treatments and are difficult to detect through visual inspection.

\section{MATERIALS AND METHODS}

Data. Newbill and Morrell (8) reported the effect of elevated temperatures on the survival of basidiomycetes that most frequently colonize untreated Douglas fir (Pseudotsuga menziesii) poles. Sterilized wood blocks ( 2.5 by 2.5 by $4 \mathrm{~cm}$ ) were inoculated with fungi and then incubated for a minimum of 4 weeks. Colonized blocks were divided into sets of three, and sets of blocks were exposed to temperatures ranging from 48.9 to $71.1^{\circ} \mathrm{C}$ for periods ranging from 0.25 to $48 \mathrm{~h}$. At selected time points, one set of blocks colonized by each fungus was removed, a thin section was cut from each of the blocks in a set, and this section was cut into 16 smaller cubes. The 48 cubes for each time-temperature combination were then cultured and examined for evidence of fungal growth 1 and 4 weeks after plating. Fungal survival was used as the measure of temperature tolerance.

Newbill and Morrell (8) selected Postia placenta and Antrodia carbonica for the heartwood portion of the experiment, because these are the two species that most frequently colonize Douglas fir heartwood. Both $P$. placenta and A. carbonica are classified as brown rot fungi. Although white rot fungi have been most extensively studied due to their potential commercial value in lignin removal processes, brown rot fungi are prevalent in many wood products and have drastic effects on wood strength reduction. In general, brown rots are perceived to be more damaging to the mechanical properties of wood because they are associated with greater strength losses at lower weight losses than are white rots (12).

Based on studies dating from the 1930s on the heat tolerance of fungi colonizing southern pines, heat treatments ranging

Table 1. Survival at elevated temperatures and various exposures periods of Postia placenta established in Douglas fir (8)

\begin{tabular}{|c|c|c|c|c|c|c|c|c|c|}
\hline \multirow[b]{2}{*}{ Exposure (h) } & \multicolumn{9}{|c|}{ Percent survival at each temperature $\left({ }^{\circ} \mathbf{C}\right)^{\mathbf{a}}$} \\
\hline & 48.9 & 51.7 & 54.4 & $\mathbf{5 7 . 2}$ & 60 & 62.8 & 65.6 & 68.4 & 71.1 \\
\hline 0.25 & 100 & 100 & 100 & 96 & 92 & 83 & 33 & 25 & 67 \\
\hline 0.5 & 100 & 100 & 96 & 92 & 100 & 92 & 8 & 25 & 0 \\
\hline 1.0 & 100 & 100 & 100 & 100 & 75 & 67 & 8 & 0 & 0 \\
\hline 1.25 & 100 & 96 & 100 & 96 & 67 & 33 & 0 & 0 & 0 \\
\hline 1.5 & 100 & 96 & 96 & 92 & 58 & 42 & 0 & 0 & 0 \\
\hline 2.0 & 100 & 100 & 100 & 92 & 25 & 0 & 0 & 0 & 0 \\
\hline 3.0 & 100 & 92 & 83 & 75 & 33 & 0 & 0 & 0 & 0 \\
\hline 4.0 & 100 & 100 & 92 & 58 & 25 & 0 & 0 & $\ldots$ & $\ldots$ \\
\hline 6.0 & 92 & 100 & 83 & 17 & 0 & 0 & $\ldots$ & $\ldots$ & $\ldots$ \\
\hline 12.0 & 100 & 92 & 33 & 0 & 0 & $\ldots$ & $\ldots$ & $\ldots$ & $\ldots$ \\
\hline 15.0 & 92 & 50 & 0 & 0 & 0 & $\ldots$ & $\ldots$ & $\ldots$ & $\ldots$ \\
\hline 18.0 & 83 & 42 & 0 & 0 & $\ldots$ & $\ldots$ & $\cdots$ & $\ldots$ & $\ldots$ \\
\hline 24.0 & 17 & 8 & 0 & 0 & $\ldots$ & $\ldots$ & $\cdots$ & $\ldots$ & $\ldots$ \\
\hline 36.0 & 8 & 0 & $\ldots$ & $\ldots$ & $\ldots$ & $\ldots$ & $\ldots$ & $\ldots$ & $\ldots$ \\
\hline 48.0 & 17 & 0 & $\ldots$ & $\ldots$ & $\ldots$ & $\ldots$ & $\ldots$ & $\ldots$ & $\ldots$ \\
\hline
\end{tabular}

a $\ldots=$ Not tested. 
from $65.6^{\circ} \mathrm{C}$ for $75 \mathrm{~min}$ to $100^{\circ} \mathrm{C}$ for $5 \mathrm{~min}$ generally have been regarded as the minimal times and internal wood temperatures required for wood sterilization. More recently, however, some fungi isolated from woodchip piles have been found to survive exposure to temperatures of $65^{\circ} \mathrm{C}$ or greater for times ranging from 8 to $72 \mathrm{~h}$, illustrating the limits of blanket wood sterilization rules (12). Both P. placenta and A. carbonica produce chlamydospores, which facilitate their survival during prolonged exposure to elevated temperatures and other adverse environmental conditions. Although these species are wood decay fungi, it is expected that their response to elevated temperatures may be representative of thermotolerant pathogenic fungi that also produce chlamydospores. The results for $P$. placenta in treated heartwood are presented in Table 1 and Figure 1. In the interests of brevity, only the P. placenta data are used to demonstrate the probabilistic modeling approach.

\section{METHODS}

The predicted response surface obtained by analyzing the $P$. placenta data in Table 1 using a standard logistic regression procedure (SAS PROC LOGISTIC, using the logit link function) is shown in Figure 2. The missing data in Table 1 corresponding
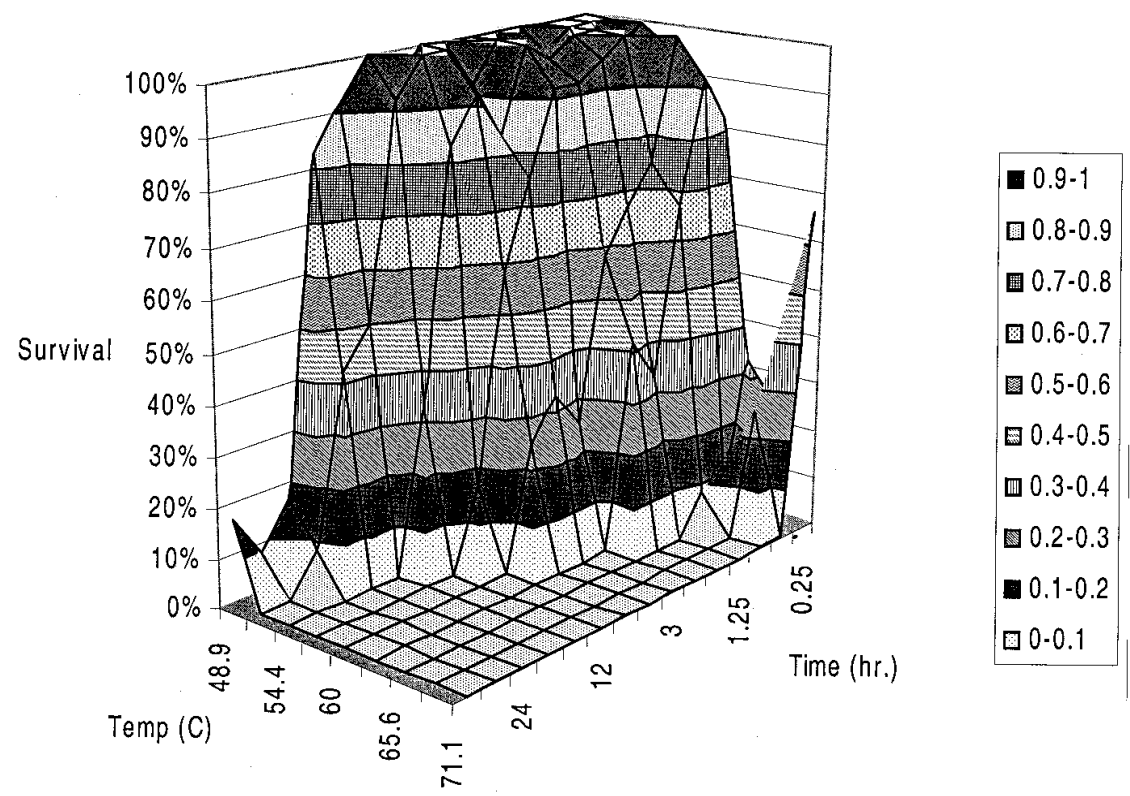

Fig. 1. Reported data for survival of Postia placenta in Douglas fir at elevated temperatures.

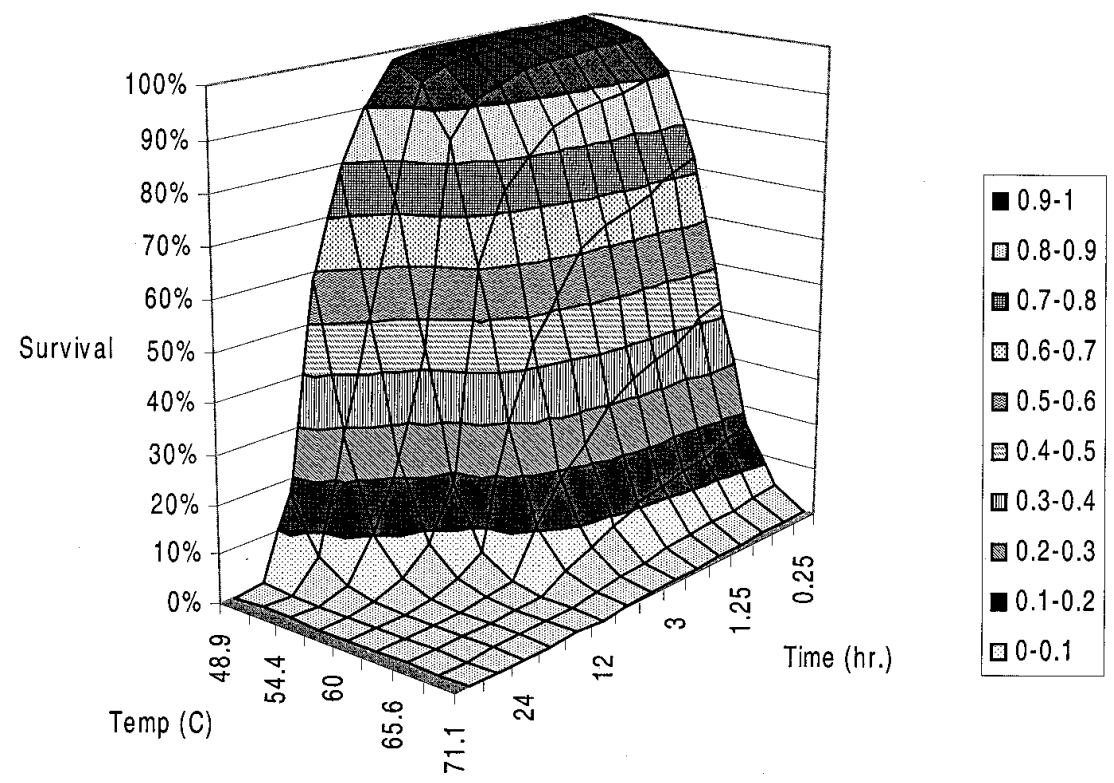

Fig. 2. Logistic response surface for survival of Postia placenta in Douglas fir at elevated temperatures. 
equation 1 applies, we constrain the model as follows: Proportion (survivalltime ${ }_{i}$,

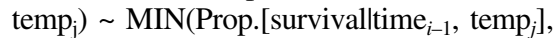
Prop.[survivalltime ${ }_{i}$, temp $\left.{ }_{j-1}\right], \beta\left[s_{i j}+1, n-\right.$ $\left.s_{i j}+1\right]$ ) (equation 2), where time ${ }_{i}$ (for $i=1$ to 15 ) ranges from 0.25 to $48 \mathrm{~h}$, and temp (for $j=1$ to 9 ) ranges from 48.9 to $71.1^{\circ} \mathrm{C}$. For example, a particular realization (iteration) of the constrained survival model (equation 2) may generate the random draws from three independent Beta distributions and the results presented in Table 2. This illustrates just a single iteration of the model for one time-temperature combination $\left(57.2^{\circ} \mathrm{C}\right.$ for $\left.2 \mathrm{~h}\right)$. However, we may generate a probabilistic response surface by performing resampling over all time and temperature combinations using Monte Carlo simulation techniques.

Monte Carlo simulation is a computerintensive technique involving repeated sampling from specified distributions using random number generation techniques. For each iteration of a Monte Carlo simulation, the computer generates a random sample from the specified distribution or distributions, analyzes the sample, and stores the results. Computational techniques such as Monte Carlo can be used to obtain a description of the sampling properties of empirical estimators when analytically derived theoretical results are not available. Monte Carlo simulations were performed with Latin Hypercube sampling $(10,000$ iterations of the $15 \times 9$ timetemperature combinations) using Palisades @ Risk (ver. 3.5.2, Newfield, NY).

For each time-temperature combination, the model yields a distribution characterizing the survival of $P$. placenta in Douglas fir. For example, at the current heat treatment standard of $71.1^{\circ} \mathrm{C}$ for $75 \mathrm{~min}$ for unmanufactured wood imports (Fed. Reg., Vol. 60, pp. 27665-27682), the estimated survival distribution has a mean of $3 \times 10^{-3}$, with a $95 \%$ confidence interval of $9 \times 10^{-5}$ to $1 \times 10^{-2}$. The response surface obtained by specifying the mean of the survival distribution for P. placenta in Douglas fir at each time-temperature combination is shown in Figure 3.

This modeling approach facilitates making inferences about the fungal survival distribution at particular time-temperature combinations. For example, the 95th percentiles of the survival distribution obtained at each time-temperature combination are shown in Figure 4. That is, $95 \%$ of the simulated survival proportions fall below the values presented. As expected, the shape of the mortality curve over exposure time is dependent on the minimum core temperature. The series of curves suggests, however, that we can interpolate within the available data to generate countless time-temperature combinations that are equivalent in terms of their performance. That is, within the bounds of the series of curves in Figure 4, the equivalent combinations would array themselves hori- zontally at any chosen level of survival between 0.1 and 0.001 .

The analysis proceeds, therefore, by capturing an appropriate percentile of the survival model output at each time-temperature combination that corresponds to the chosen confidence level. For the purposes of this example, the 95th percentile is used. The complement of each of these values corresponds to a lower-confidence

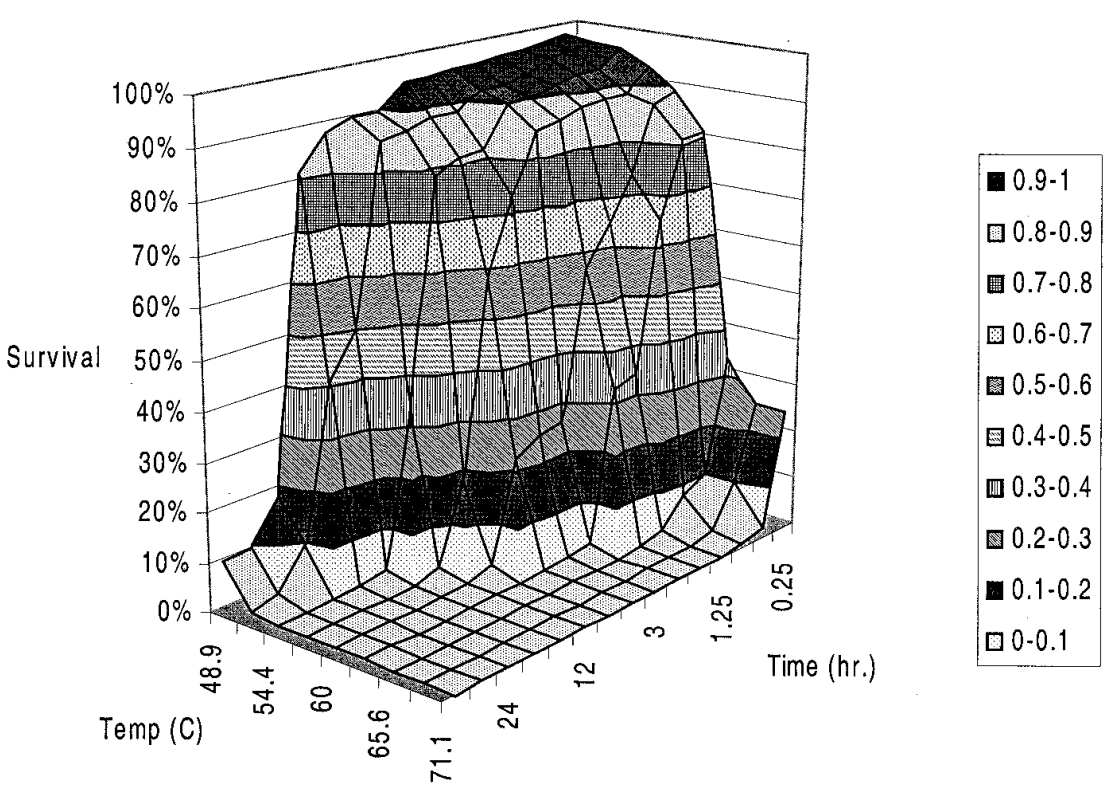

Fig. 3. Mean Beta model response surface for survival of Postia placenta in Douglas fir at elevated temperatures.

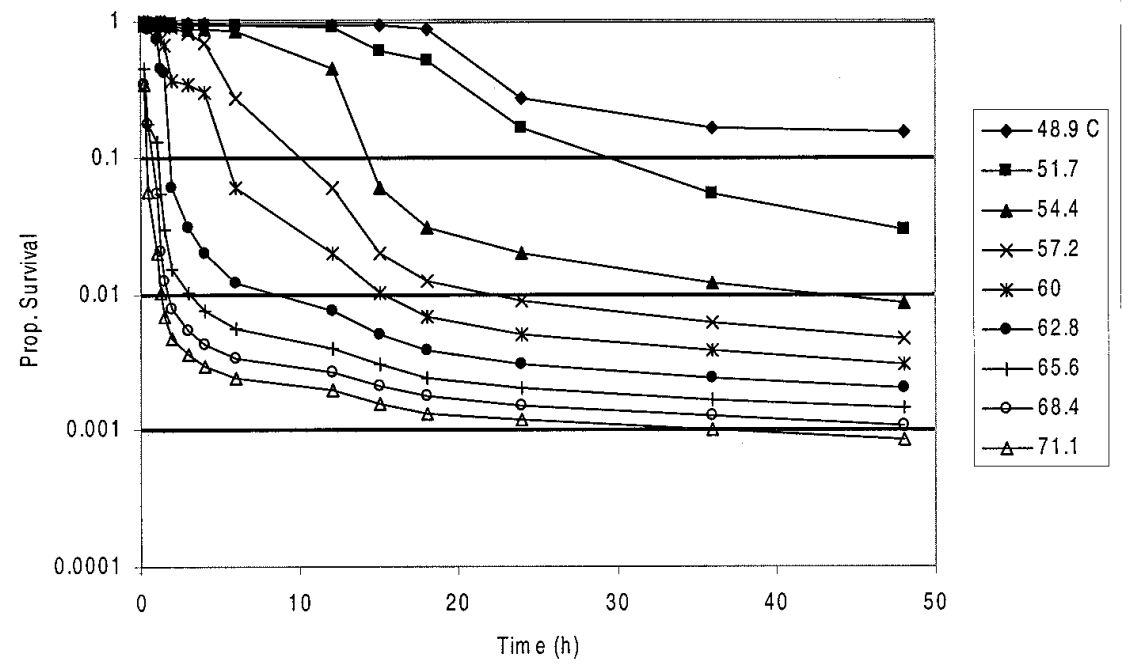

Fig. 4. Survival curves (95th percentile) for Postia placenta in Douglas fir.

Table 2. Illustrative realization of constrained survival model ${ }^{\mathrm{a}}$

\begin{tabular}{lccc}
\hline Time-temperature combination & Survival $(\boldsymbol{s} / \boldsymbol{n})$ & $\beta(\boldsymbol{s}+\mathbf{1}, \boldsymbol{n}-\mathbf{s}+\mathbf{1})$ & $\begin{array}{c}\text { Random draw from } \\
\text { Beta distribution }\end{array}$ \\
\hline $57.2^{\circ} \mathrm{C}, 1.5 \mathrm{~h}$ & $44 / 48=92 \%$ & $\beta(45,5)$ & 0.83 \\
$54.4^{\circ} \mathrm{C}, 2 \mathrm{~h}$ & $48 / 48=100 \%$ & $\beta(49,1)$ & 0.95 \\
$57.2^{\circ} \mathrm{C}, 2 \mathrm{~h}$ & $44 / 48=92 \%$ & $\beta(45,5)$ & 0.86 \\
\hline
\end{tabular}

${ }^{a}$ Proportion(survivel $\left.57.2^{\circ} \mathrm{C}, 2 \mathrm{~h}\right)=\operatorname{MIN}(0.83,0.95,0.86)=0.83$. 
limit on the proportional lethality achieved at each time-temperature combination (Table 3). At each temperature that achieves a minimum specified percent lethality over some exposure duration, we can estimate the time required to achieve the target lethality rate by interpolation. For the purposes of this analysis, this result is obtained by specifying an empirical cumulative distribution (equation 3 ) with a minimum value of $0 \mathrm{~h}$, a maximum value of $100 \mathrm{~h}$, and discrete cumulative percentiles at each time increment reported in Table 3: Cumulative(min, $\max ,\{x\},\{p\})$ (equation 3).

At $60^{\circ} \mathrm{C}$, for example, the distribution is specified as: $\min =0 ; \max =100 ;\{x\}=$ $0.25,0.5, \ldots, 48 ;\{p\}=0.0538,0.0768, \ldots$, 0.9970 . After simulating on the distribution for each temperature, the 90th and 99th percentiles are captured to obtain estimates of the time $(h)$ required at each temperature to provide $95 \%$ confidence that the lethality achieved is at least 90 and $99 \%$, respectively. By taking the log transform of these exposure periods and plotting them against temperature, we can estimate a line fit to the simulated data by means of ordinary least squares regression: $\log _{10}($ time $[\mathrm{h}])=b_{0}+b_{1} \times($ temperature $\left[{ }^{\circ} \mathrm{C}\right]$ ) (equation 4$)$.

Note that the regression equation estimates the $\log$ of the time required to achieve the targeted lethality at a given temperature; therefore, the log transformation must be reversed to estimate the requisite time in hours.

\section{RESULTS}

The results of this analysis are summarized in Table 4 and displayed in Figure 5. The method described provides one approach to estimating time-temperature combinations resulting in equivalent levels of phytosanitary protection-hence the term "iso-safety" curves. Each time-temperature combination corresponding to a point along the solid line in Figure 5 is estimated to provide $95 \%$ confidence of achieving at least $90 \%$ lethality-or equivalently, $95 \%$ confidence of a heat treatment failure rate of no more than $10 \%$ - for P. placenta in Douglas fir. Likewise, each point along the dashed line in Figure 5 is estimated to provide $95 \%$ confidence of a heat treatment failure rate of no more than $1 \%$ for $P$. placenta in Douglas fir. As suggested by Figure 4, there is a series of long duration-high temperature combinations that would provide $95 \%$ confidence of a failure rate of no more than $0.1 \%$ as well. This is not to suggest that such treatments would be feasible for all applications. It serves to point out, however, that the analysis could be reproduced for countless alternative combinations of confidence level and treatment failure rate, if desired.

\section{DISCUSSION}

This analytic approach is limited to cases in which data on the response to treatment are available over several levels of the input variables. Many experimental studies, however, are designed to establish only whether there exists a statistically significant difference in the output obtained from a few levels of the input variables. The traditional approach has emphasized replication (to increase the power of statistical comparisons of discrete alternatives) at the expense of coverage and provides minimal information relevant to modeling the response surface over the entire range of concern to policymakers. This points to the need for future experimental studies on the performance of phy-

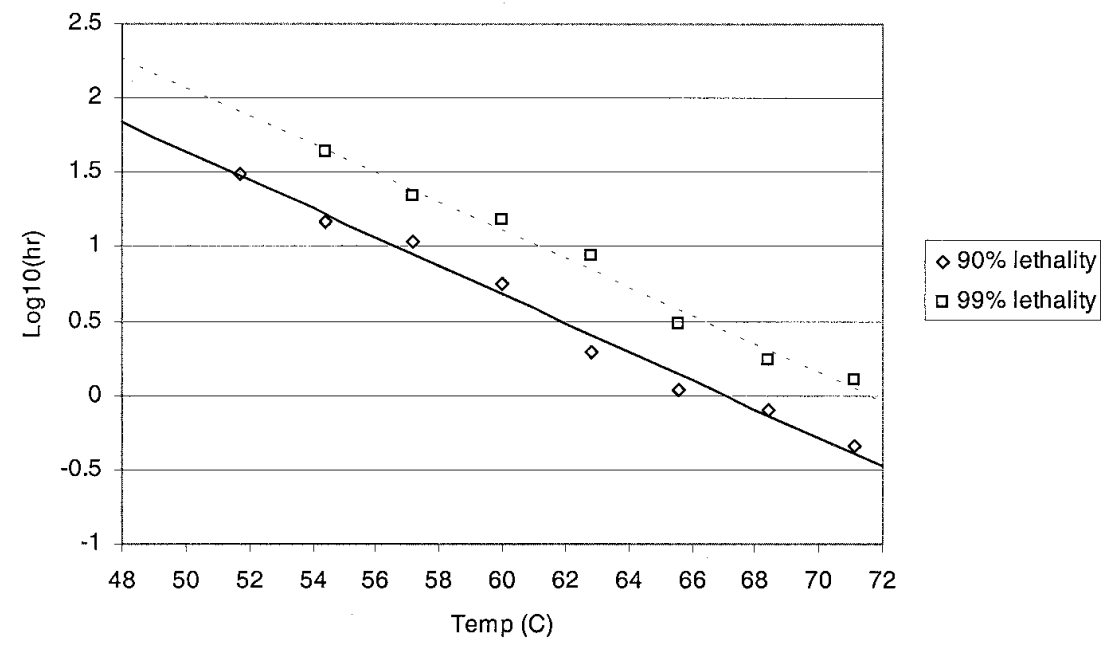

Fig. 5. Iso-safety curves (95th percentile) for Postia placenta in Douglas fir.

Table 4. Iso-safety curve results ${ }^{\mathrm{a}}$

\begin{tabular}{lcc}
\hline $\mathbf{9 5 \%}$ confidence of achieving at least & 90\% lethality & 99\% lethality \\
\hline$b_{0}$ & 6.462685 & 6.877294 \\
$b_{1}$ & -0.09641 & -0.09607 \\
$P^{* *}$ & $9.61 \mathrm{E}-07$ & $8.96 \mathrm{E}-06$ \\
\hline
\end{tabular}

${ }^{\mathrm{a}} \log _{10}($ exposure period $[\mathrm{h}])=b_{0}+b_{1} \times\left(\right.$ temperature $\left.\left[{ }^{\circ} \mathrm{C}\right]\right) ; * *$ ordinary least squares regression model significance.

Table 3. 95\% Lower confidence limit for lethality of Postia placenta established in Douglas fir

\begin{tabular}{|c|c|c|c|c|c|c|c|c|c|}
\hline \multirow[b]{2}{*}{ Exposure (h) } & \multicolumn{9}{|c|}{ Proportions at each temperature $\left({ }^{\circ} \mathrm{C}\right)$} \\
\hline & 48.9 & 51.7 & 54.4 & 57.2 & 60 & 62.8 & 65.6 & 68.4 & 71.1 \\
\hline 0.25 & 0.0010 & 0.0053 & 0.0096 & 0.0259 & 0.0538 & 0.1101 & 0.5472 & 0.6604 & 0.6604 \\
\hline 0.5 & 0.0051 & 0.0130 & 0.0300 & 0.0614 & 0.0768 & 0.1224 & 0.8229 & 0.8276 & 0.9436 \\
\hline 1.0 & 0.0092 & 0.0185 & 0.0351 & 0.0632 & 0.1681 & 0.2572 & 0.8705 & 0.9457 & 0.9799 \\
\hline 1.25 & 0.0126 & 0.0332 & 0.0455 & 0.0722 & 0.2564 & 0.5473 & 0.9465 & 0.9797 & 0.9898 \\
\hline 1.5 & 0.0159 & 0.0439 & 0.0582 & 0.0888 & 0.3371 & 0.5764 & 0.9702 & 0.9876 & 0.9933 \\
\hline 2.0 & 0.0187 & 0.0456 & 0.0595 & 0.0966 & 0.6337 & 0.9407 & 0.9847 & 0.9923 & 0.9954 \\
\hline 3.0 & 0.0215 & 0.0637 & 0.1150 & 0.1846 & 0.6595 & 0.9697 & 0.9898 & 0.9946 & 0.9964 \\
\hline 4.0 & 0.0238 & 0.0646 & 0.1208 & 0.3146 & 0.7027 & 0.9801 & 0.9924 & 0.9957 & 0.9971 \\
\hline 6.0 & 0.0502 & 0.0782 & 0.1464 & 0.7247 & 0.9408 & 0.9880 & 0.9945 & 0.9966 & 0.9976 \\
\hline 12.0 & 0.0513 & 0.0889 & 0.5472 & 0.9407 & 0.9798 & 0.9924 & 0.9960 & 0.9973 & 0.9980 \\
\hline 15.0 & 0.0690 & 0.3847 & 0.9407 & 0.9800 & 0.9899 & 0.9950 & 0.9970 & 0.9979 & 0.9984 \\
\hline 18.0 & 0.1163 & 0.4933 & 0.9698 & 0.9875 & 0.9933 & 0.9962 & 0.9976 & 0.9982 & 0.9987 \\
\hline 24.0 & 0.7247 & 0.8371 & 0.9799 & 0.9911 & 0.9949 & 0.9970 & 0.9980 & 0.9985 & 0.9988 \\
\hline 36.0 & 0.8376 & 0.9460 & 0.9879 & 0.9939 & 0.9962 & 0.9976 & 0.9983 & 0.9987 & 0.9990 \\
\hline 48.0 & 0.8468 & 0.9701 & 0.9913 & 0.9953 & 0.9970 & 0.9980 & 0.9986 & 0.9989 & 0.9991 \\
\hline
\end{tabular}


tosanitary treatments to more carefully consider the tradeoff between replication and coverage.

The illustrative analysis presented also is limited in that it does not address the uncertainty surrounding heat treatment performance introduced by extrapolating from laboratory observations to field operations. Under experimental protocols, for example, the heated material may be rapidly cooled by immersion in ice water as soon as it has achieved the minimum core temperature for the specified exposure period. Under operational conditions, however, there would be some additional lethality expected during passive cooling. This draft analysis also does not take into account the initial inoculum levels achieved under the experimental protocol (8). If the initial levels are such that they would rapidly and substantially deteriorate the mechanical properties of the solid wood (and therefore result in its disposal), then less stringent heating may be required to achieve the designated level of protection under operational conditions. Alternatively, additional heating might be indicated if higher levels of fungal colonization may be encountered in unmanufactured wood materials that remain serviceable for a sufficient period of time to act as a vehicle of introducing the pest to a new environment.

The failure rate estimated for the current heat treatment standard $\left(71.1^{\circ} \mathrm{C}\right.$ for $\left.1.25 \mathrm{~h}\right)$ may appear somewhat higher than expected, with a mean value of $0.3 \%$. There are at least three possibilities: (i) the model may overstate the true failure rate (e.g., due to factors unaccounted for, such as additional mortality during passive cooling), (ii) the consequences of failure as defined here-the ability to culture the organism from a treated sample-are generally negligible due to low levels of sur- viving pests that fail to grow out after treatment to substantial levels, and (iii) both $\mathrm{i}$ and ii.

In conclusion, it should be noted that, in the absence of rigorous risk reduction analysis, there is no formal linkage between an identified risk and the measures designed to achieve a country's appropriate level of phytosanitary protection. The preferred level of protection may be revealed implicitly, however, by the combination of measures required in a particular situation. The inferred level of protection may be higher or lower than the levels considered by the country to be appropriate in comparable situations. In this case, the SPS Agreement requires that the country be prepared to demonstrate that the distinction in the appropriate level of protection is not arbitrary or unjustifiable. The WTO Committee on Sanitary and Phytosanitary Measures (2000) notes that the "establishment of different levels of protection in the face of similar risks in different situations may raise the question as to whether the differences in the levels of protection are arbitrary or unjustifiable." If the distinction is determined to be arbitrary or unjustifiable, the country must be prepared to demonstrate that the measure does not result in discrimination among members, or in a disguised restriction on international trade. Although no precise definition of "discrimination or a disguised restriction on international trade" currently exists, substantial differences in the levels of protection considered to be appropriate in different situations, the existence of arbitrary or unjustifiable differences in the levels of protection considered by a member as appropriate in different situations, or insufficient scientific justification for SPS measures are considered "warning signals" that could indicate the existence of discrimination or a disguised restriction on trade (2).

\section{LITERATURE CITED}

1. Commission on Risk Assessment and Risk Management. 1997. Risk Assessment and Risk Management in Regulatory DecisionMaking. Commission on Risk Assessment and Risk Management, Washington, DC.

2. Committee on Sanitary and Phytosanitary Measures. 2000. Guidelines to Further the Practical Implementation of Article 5.5. World Trade Organization, Geneva.

3. Foreign Agriculture Service. 2000. Solid Wood Packing Material. Wood Products: International Trade and Foreign Markets. United States Department of Agriculture, Washington, DC

4. Interim Commission on Phytosanitary Measures. 2001. Report of the Third Interim Commission on Phytosanitary Measures. United Nations Food and Agriculture Organization, Rome.

5. International Plant Pest Convention. 1996 Guidelines for Pest Risk Analysis. United Nations Food and Agriculture Organization, Rome.

6. International Plant Pest Convention. 1999. Pest Risk Analysis for Quarantine Pests: Draft Standard for Country Consultation. United Nations Food and Agriculture Organization, Rome.

7. Morrell, J. J. 1995. Importation of unprocessed $\log$ s into North America: a review of pest mitigation procedures and their efficacy. For. Prod. J. 45:41-50.

8. Newbill, M. A., and Morrell, J. J. 1991. Effect of elevated temperatures on survival of basidiomycetes that colonize untreated Douglas-fir poles. For. Prod. J. 41:31-33.

9. Powell, M. 1999. Science at EPA: Information in the Regulatory Process. Resources for the Future, Washington, DC.

10. Vose, D. 2000. Risk Analysis: A Quantitative Guide. John Wiley \& Sons., Ltd., Chichester, England.

11. World Trade Organization. 1994. Agreement on the Application of Sanitary and Phytosanitary Measures. World Trade Organization, Geneva.

12. Zabel, R. A., and Morrell, J. J. 1992. Wood Microbiology: Decay and Its Prevention. Academic Press, Inc., San Diego, CA. 